Pacific Journal of Mathematics

THE ASYMPTOTIC BEHAVIOUR OF SOLUTIONS TO LINEAR
SYSTEMS OF ORDINARY DIFFERENTIAL EQUATIONS 


\title{
THE ASYMPTOTIC BEHAVIOUR OF SOLUTIONS TO LINEAR SYSTEMS OF ORDINARY DIFFERENTIAL EQUATIONS
}

\author{
JACK W. MACKI AND JAMes S. MuldowneY
}

\begin{abstract}
This paper is concerned with the system of differential equations
\end{abstract}

$$
x^{\prime}=A(t) x, \quad t \in[0, \omega)
$$

where $A(t)$ is an $n \times n$ matrix of locally integrable complexvalued functions on $[0, \omega)$ and $x(t)$ is an $n$-dimensional column vector. The class of matrices $A(t)$ such that $(1)$ has a nontrivial solution $x_{0}(t)$ satisfying $\lim _{t \rightarrow \omega}\left|x_{0}(t)\right|=0$ is denoted by $\Omega_{0}$; the class of matrices $A(t)$ such that $(1)$ has a solution $x_{\infty}(t)$ satisfying $\lim _{t \rightarrow \omega}\left|x_{\infty}(t)\right|=+\infty$ is denoted by $\Omega_{\infty}$. If $P$ is a projection then $\Omega P_{0}$ denotes the class of matrices $A(t)$ such that $(1)$ has a nontrivial solution $x_{0}(t)$ satisfying $\lim _{t \rightarrow \omega}\left|P x_{0}(t)\right|=0$. Sufficient conditions are given for $A(t) \in \Omega_{0}, A(t) \in \Omega_{\infty}$ and $A(t) \epsilon$ $\Omega P_{0}$; the result, obtained include as special cases theorems of Coppel, Hartman, and Milloux.

Throughout, || || will denote the Euclidean norm and | | will be used for any other norm (which of course must be topologically equivalent to \|\| ) on the vector space of complex $n$-tuples. If $B$ is an $n \times n$ matrix, then $B^{*}$ denotes its Hermitian conjugate and $\operatorname{Tr} B$ its trace; if $c$ is a complex number then $\operatorname{Re} c$ is its real part.

Lemma 1. (Compare Hartman [3], p. 501). Let $\left\{t_{k}\right\}$ be a sequence in $[0, \omega)$ converging to $\omega$.

(a) Suppose $0 \leqq \lim _{k \rightarrow \infty}\left\|x\left(t_{k}\right)\right\|<+\infty$ exists for each solution $x(t)$ of $(1)$; then there exists a nontrivial solution $x_{0}(t)$ such that

$$
\lim _{k \rightarrow \infty}\left\|x_{0}\left(t_{k}\right)\right\|=0
$$

if and only if

$$
\lim _{k \rightarrow \infty} \operatorname{Re} \int_{0}^{t_{k}} \operatorname{Tr} A=-\infty .
$$

(b) Suppose $0 \leqq \lim _{k \rightarrow \infty}\left\|x\left(t_{k}\right)\right\| \leqq+\infty$ exists for each solution $x(t)$ of $(1)$; then there exists a solution $x_{\infty}(t)$ such that

$$
\lim _{k \rightarrow \infty}\left\|x_{\infty}\left(t_{k}\right)\right\|=+\infty
$$




$$
\lim _{k \rightarrow \infty} \operatorname{Re} \int_{0}^{t_{k}} \operatorname{Tr} A=+\infty
$$

Proof. (The proof parallels that of Hartman). (a) Since

$$
0 \leqq \lim _{k-\infty} x^{*}\left(t_{k}\right) x\left(t_{k}\right)<+\infty
$$

exists for each solution of (1) it is easy to see that

$$
0 \leqq\left|\lim _{k-\infty} x_{p}^{*}\left(t_{k}\right) x_{q}\left(t_{k}\right)\right|<+\infty
$$

exists for any solutions $x_{p}(t), x_{q}(t)$. Thus if $\Phi(t)$ is the fundamental matrix of (1) satisfying $\Phi(0)=E$, we know that $\lim _{k \rightarrow \infty} \Phi^{*}\left(t_{k}\right) \Phi\left(t_{k}\right)=H$ exists, each element of $H$ is finite, and $H$ is Hermitian. Also,

$$
\lim _{k \rightarrow \infty}\left(\operatorname{det} \Phi\left(t_{k}\right)\right)^{2}=\lim _{k \rightarrow \infty}\left(\operatorname{det} \Phi^{*} \Phi\right)\left(t_{k}\right)=\operatorname{det} H .
$$

Hence, by the Liouville-Jacobi formula ([3], p. 46),

$$
-\infty \leqq \lim _{k \rightarrow \infty} \operatorname{Re} \int_{0}^{t_{k}} \operatorname{Tr} A<+\infty
$$

exists and

$$
\operatorname{det} H=\lim _{k \rightarrow \infty} \exp \left[2 \operatorname{Re} \int_{0}^{t_{k}} \operatorname{Tr} A\right] .
$$

Since $x(t)$ solves (1) if and only if $x(t)=\Phi(t) c, c=x(0)$, we have

$$
0 \leqq \lim _{k \rightarrow \infty}\left\|x\left(t_{k}\right)\right\|^{2}=\lim _{k \rightarrow \infty} c^{*} \Phi^{*}\left(t_{k}\right) \Phi\left(t_{k}\right) c=c^{*} H c .
$$

$H$ is consequently nonnegative definite, so

$$
\exists c \neq 0 \text { such that } c^{*} H c=0 \Longleftrightarrow \operatorname{det} H=0,
$$

i.e., if and only if $\lim _{k \rightarrow \infty} \operatorname{Re} \int_{0}^{t_{k}} \operatorname{Tr} A=-\infty$.

(b) If it were the case that $\lim _{k \rightarrow \infty}\left\|x\left(t_{k}\right)\right\|<+\infty$ for all solutions of (1) then part (a) above shows that $\lim _{k \rightarrow \infty} \operatorname{Re} \int_{0}^{t_{k}} \operatorname{Tr} A<+\infty$.

REMARK. Note that the above proof depended in an essential way on the fact that the Euclidean norm is generated by an inner product.

Theorem 1. (a) Suppose (1) is stable and each solution $x(t)$ has the property:

$$
\text { If } \liminf _{t \rightarrow \omega}|x(t)|=0 \text { then } \lim _{t \rightarrow \omega}|x(t)|=0 .
$$




$$
A(t) \in \Omega_{0} \Longleftrightarrow \liminf _{t \rightarrow \omega} \operatorname{Re} \int_{0}^{t} \operatorname{Tr} A=-\infty .
$$

(b) Suppose solutions of (1) have the property:

$$
\text { If } \limsup _{t \rightarrow \omega}|x(t)|=+\infty \text { then } \lim _{t \rightarrow \omega}|x(t)|=+\infty \text {. }
$$

Then

$$
A(t) \in \Omega_{\infty} \Longleftarrow \limsup _{t \rightarrow \omega} \operatorname{Re} \int_{0}^{t} \operatorname{Tr} A=+\infty .
$$

Proof.

(a) Suppose that no solution satisfies $\lim _{t \rightarrow \omega}|x(t)|=0$; then by (2) $\lim \inf _{t \rightarrow \omega}|x(t)|>0$ for each solution, and so $\lim \inf _{t \rightarrow \omega}\|x(t)\|>0$ for each solution. By Lemma 1, we cannot have

$$
\lim _{k \rightarrow \infty} \operatorname{Re} \int_{0}^{t_{k}} \operatorname{Tr} A=-\infty
$$

for any sequence $\left\{t_{k}\right\}$ converging to $\omega$, so $\lim \inf _{t \rightarrow \omega} \operatorname{Re} \int_{0}^{t} \operatorname{Tr} A>-\infty$.

Conversely, suppose $\lim _{t \rightarrow \omega}\left|x_{0}(t)\right|=0$ for a solution $x_{0}(t)$. Let $\Phi(t)$ be a fundamental matrix. Since all solutions are bounded, we have

$$
0=\lim _{t \rightarrow \omega}|\operatorname{det} \Phi(t)|=\lim _{t \rightarrow \omega}|\operatorname{det} \Phi(0)| \exp \left(\operatorname{Re} \int_{0}^{t} \operatorname{Tr} A\right)
$$

(b) If all solutions are bounded then we must have

$$
\lim _{t \rightarrow \omega} \sup \operatorname{Re} \int_{0}^{t} \operatorname{Tr} A<+\infty
$$

by part (b) of Lemma 1 . So the negation of $\left(^{*}\right)$ implies the existence of a solution $x_{\infty}(t)$ for which $\lim \sup _{t \rightarrow \omega}\left|x_{\infty}(t)\right|=+\infty$ which, by (3), implies that $\lim _{t \rightarrow \omega}\left|x_{\infty}(t)\right|=+\infty$.

COROLlaRY 1.1. If (1) is stable and satisfies condition (2) then

$$
\liminf _{t \rightarrow \omega} \operatorname{Re} \int_{0}^{t} \operatorname{Tr} A=-\infty \Longrightarrow \lim _{t \rightarrow \omega} \operatorname{Re} \int_{0}^{t} \operatorname{Tr} A=-\infty .
$$

Proof. $\quad \liminf _{t \rightarrow \omega} \operatorname{Re} \int_{0}^{t} \operatorname{Tr} A=-\infty$ implies the existence of a solution $x_{0}(t)$ such that $\lim _{t \rightarrow \omega}\left|x_{0}(t)\right|=0$. If $\Phi(t)$ is a fundamental matrix for equation (1), then clearly $\lim _{t \rightarrow \omega}|\operatorname{det} \Phi(t)|=0$ and hence

$$
\lim _{t \rightarrow \infty} \operatorname{Re} \int_{0}^{t} \operatorname{Tr} A=-\infty
$$

Corollary 1.2. (Hartman [3], p. 501; Coppel [2], p. 60). 
Suppose that $0 \leqq \lim _{t \rightarrow \omega}|x(t)|<+\infty$ exists for each solution of (1). Then

$$
A(t) \in \Omega_{0} \Longleftrightarrow \lim _{t \rightarrow \omega} \operatorname{Re} \int_{0}^{t} \operatorname{Tr} A=-\infty .
$$

(b) Suppose that $0 \leqq \lim _{t \rightarrow \omega}|x(t)| \leqq+\infty$ exists for each solution of (1). Then

$$
A(t) \in \Omega_{\infty} \Longleftarrow \lim _{t \rightarrow \omega} \operatorname{Re} \int_{0}^{t} \operatorname{Tr} A=+\infty
$$

COROLlary 1.3. Suppose (1) is uniformly stable ([2] p. 51). Then

$$
A(t) \in \Omega_{0} \Longleftrightarrow \lim _{t \rightarrow \omega} \operatorname{Re} \int_{0}^{t} \operatorname{Tr} A=-\infty .
$$

Proof. It suffices to show that if (1) is uniformly stable then it satisfies (2). Uniform stability means that, for each $\varepsilon>0$, there exists a $\delta(\varepsilon)>0$ such that, if $\left|x\left(t_{0}\right)\right|<\delta(\varepsilon)$, then $|x(t)|<\varepsilon$ for all $t \in$ $\left[t_{0}, \omega\right)$. If $\liminf _{t \rightarrow \omega}|x(t)|=0$ then, for each $\varepsilon>0$, there exists a $t_{\varepsilon} \in(0, \omega)$ such that $\left|x\left(t_{\varepsilon}\right)\right|<\delta(\varepsilon)$ and so $|x(t)|<\varepsilon$ if $t \in\left[t_{\varepsilon}, \omega\right)$; thus $\lim _{t \rightarrow \omega}|x(t)|=0$.

REMARK ( i ). Corollary 1.1 implies in particular that if

$$
-\infty=\liminf _{t \rightarrow \omega} \operatorname{Re} \int_{0}^{t} \operatorname{Tr} A<\lim \sup _{t \rightarrow \omega} \operatorname{Re} \int_{0}^{t} \operatorname{Tr} A,
$$

then either (1) is unstable (i.e., it has an unbounded solution) or it is stable but does not have the property (2); thus it is neither asymptotically nor uniformly stable (cf. Corollary 1.3).

REMARK (ii). Although Theorem 1 requires a somewhat stronger condition than stability, it is clear that if (1) is stable and condition (2) holds, it does not necessarily follow that (1) is uniformly stable. For example, condition (2) and stability are satisfied if (1) is asymptotically stable, but this does not imply that (1) is uniformly stable (cf. Coppel [2], p. 52).

REMARK (iii). Corollary 1.2 was proved by Hartman for Euclidean norms ([4]; [3], p. 501), and part (a) of this corollary was proved by Coppel for general norms ([2], p. 60).

REMARK (iv). $-A^{*}(t) \in \Omega_{0} \Longrightarrow A(t) \in \Omega_{\infty}$. Suppose the adjoint equation of $(1), \widetilde{x}^{\prime}=-A^{*}(t) \widetilde{x}$, has a solution $\widetilde{x}_{0}(t)$ such that 


$$
\lim _{t \rightarrow \omega}\left\|\widetilde{x}_{0}(t)\right\|=0 \text {. }
$$

Then there exists a solution $x_{\infty}(t)$ of (1) such that

$$
1=\tilde{x}_{0}^{*}(t) x_{\infty}(t) \leqq\left\|\widetilde{x}_{0}(t)\right\|\left\|x_{\infty}(t)\right\|,
$$

and thus $\lim _{t \rightarrow \omega}\left\|x_{\infty}(t)\right\|=+\infty$. (cf. [1], p. 71).

Hartman ([3], p. 501) observes that the conditions of Corollary 1.2(a) ((b)) are satisfied for the Euclidean norm when the matrix $\left[A+A^{*}\right](t)$ is nonpositive (nonnegative) definite for all $t \in[0, \omega)$. Further sufficient conditions involving the logarithmic norm, $\mu$, due to Lozinskii [5] (cf. Coppel [2], pp. 41, 58-59) may be obtained. If $B$ is any $n \times n$ matrix, and $|B|$ is the operator norm of $B$ induced by the vector norm || , i.e., $|B|=\sup _{|x|=1}|B x|$, then

$$
\mu(B)=\lim _{h \rightarrow 0^{+}}(|I+h B|-1) / h,
$$

where $I$ is the $n \times n$ identity matrix. If $|x|$ is one of $\sup _{i}\left|x^{i}\right|, \sum_{i}\left|x^{i}\right|$, or $\|x\|$ respectively, then the corresponding $\mu(B)$ is given by (see Coppel [2], p. 41):

$$
\sup _{i}\left(\operatorname{Re} b_{i i}+\sum_{k \neq i}\left|b_{i k}\right|\right), \sup _{i}\left(\operatorname{Re} b_{i i}+\sum_{k \neq i}\left|b_{k i}\right|\right),
$$

or $\frac{1}{2} \Lambda\left(B+B^{*}\right)$, where $\Lambda(C)$ denotes the largest eigenvalue of $C$. As is shown in Coppel ([2], p. 58), if $x(t)$ is a solution of (1), then

$$
|x(t)| \exp \left(-\int_{0}^{t} \mu(A)\right),|x(t)| \exp \left(\int_{0}^{t} \mu(-A)\right)
$$

are nonincreasing and nondecreasing, respectively. The hypotheses of part (a) of Theorem 1 are satisfied if there exists a constant $M$, independent of both $t$ and $t_{0}$, such that

$$
\int_{t_{0}}^{t} \mu(A) \leqq M \text { for } 0 \leqq t_{0} \leqq t<\omega,
$$

(in fact, (1) is then uniformly stable), and the hypotheses of part (b) of Theorem 1 are satisfied if there exists an $N$, independent of $t_{0}$ and $t$, such that

$$
\int_{t_{0}}^{t} \mu(-A) \leqq N \text { for } 0 \leqq t_{0} \leqq t<\omega .
$$

Furthermore, $0 \leqq \lim _{t \rightarrow \omega}|x(t)|<+\infty$ exists for every solution if

$$
\begin{gathered}
-\infty \leqq \lim _{t \rightarrow \omega} \int_{0}^{t} \mu(A)<+\infty \text { exists; while } \\
0<\lim _{t \rightarrow \omega}|x(t)| \leqq+\infty \text { exists if }
\end{gathered}
$$




$$
-\infty \leqq \lim _{t \rightarrow \omega} \int_{0}^{t} \mu(-A)<+\infty \text { exists }
$$

These facts can be applied, using Theorem 1 and its corollaries, to obtain concrete conditions under which $A(t) \in \Omega_{0}$ or $A(t) \in \Omega_{\infty}$.

Although Theorem 1 and its corollaries furnish sufficient conditions for $A \in \Omega_{0}$ and $A \in \Omega_{\infty}$, it is clear that these are not necessary conditions. For example, in the case of a constant matrix $A$ with $\omega=+\infty, A \in \Omega_{0}$ if and only if $\operatorname{Re} \mu<0$ for some eigenvalue $\mu$ of $A$; while $A \in \Omega_{\infty}$ if and only if $\operatorname{Re} \mu \geqq 0$ for some eigenvalue $\mu$ of $A$ and, if $\operatorname{Re} \mu=0, \mu$ occurs in a nondiagonal Jordan block in the normal form of $A$ (cf. [1], p. 77). However, the hypotheses of Theorem 1 and its corollaries are not invariant under changes of the dependent variable in (1); this observation allows us to broaden considerably the class of equations for which Theorem 1 gives information.

THEOREM 2. Let $\Gamma(t)$ be a nonsingular $n \times n$ matrix of absolutely continuous complex-valued functions on $[0, \omega)$, and define

$$
B=\Gamma^{\prime} \Gamma^{-1}+\Gamma A \Gamma^{-1} \equiv \Gamma \triangle A .
$$

(a) If $|\Gamma(t) x| \leqq K|x|$, for some constant $K$, for all $x$ and all $t \geqq 0$, then:

$$
\begin{aligned}
& A \in \Omega_{0} \Longrightarrow B \in \Omega_{0}, \\
& A \in \Omega_{\infty} \Longleftarrow B \in \Omega_{\infty} .
\end{aligned}
$$

(b) If $|\Gamma(t) x| \geqq k|x|$, for some constant $k(\neq 0)$, for all $x$ and all $t \geqq 0$ then:

$$
\begin{aligned}
& B \in \Omega_{0} \Longrightarrow A \in \Omega_{0}, \\
& B \in \Omega_{\infty} \Longleftarrow A \in \Omega_{\infty} .
\end{aligned}
$$

(c) If $k|x| \leqq|\Gamma(t) x| \leqq K|x|$ for some constants $k(\neq 0)$ and $K$, for all $x$ and all $t \geqq 0$, then:

$$
\begin{aligned}
& B \in \Omega_{0} \Longleftrightarrow A \in \Omega_{0} \\
& B \in \Omega_{\infty} \Longleftrightarrow A \in \Omega_{\infty}
\end{aligned}
$$

(d) If $|\Gamma(t) x| \geqq k|P x|$ for some constant $k(\neq 0)$ and all $x$ and $t \geqq 0$, where $P$ is a projection, then

$$
B \in \Omega_{0} \Longrightarrow A \in \Omega P_{0} .
$$

Proof. $y(t)$ is a solution of

$$
y^{\prime}=\Gamma \triangle A(t) y
$$


if and only if $y(t)=\Gamma(t) x(t)$ where $x(t)$ is a solution of (1), so that, in case (a), we have $|y(t)| \leqq K|x(t)|$ for corresponding solutions of (5) and (1), and the result is obvious. The argument is similar in cases (b), (c) and (d) and, in fact, (a) and (b) are equivalent since $B=\Gamma \triangle A$ if and only if $A=\Gamma^{-1} \triangle B$.

The change of variable used above has been studied from several points of view, but always under (at least) the assumption in part (c) of the Theorem. This assumption implies that the class of allowable transformations forms a group, or, equivalently, that the relation of "kinematic similarily" $-A \sim B$ if and only if there exists a $\Gamma$, satisfying the assumptions in (c), such that $B=\Gamma \triangle A$-is an equivalence relation. This concept was developed by Markus [6]. For a full discussion with references, see Sansone and Conti ([8], p. 457). The conditions of Theorem 1 are invariants of kinematic similarity, but are not invariant under the assumptions of parts (a), (b) and (d) of Theorem 2; thus, less restrictive conditions than those in (c) are more useful in the present context. For example, given a matrix $A(t)$ which satisfies the conditions of part (a) of Corollary 1.2, then

$$
\{\Gamma \triangle A:|\Gamma(t) x| \leqq K|x| \text { for some } K=K(\Gamma)\} \subset \Omega_{0} \text {. }
$$

Notice that stability is preserved under this class of transformations, but the property described in (2) is not.

Theorem 3 below will illustrate how Theorems 1 and 2 may be used in practice to obtain information on the asymptotic nature of solutions to differential equations. The following simple lemma will be useful.

Lemma 2. If $\Gamma$ is a nonsingular matrix of absolutely continuous functions on $[0, \omega)$, with $\operatorname{det} \Gamma(t)>0$, then

$$
\operatorname{Tr}\left(\Gamma^{\prime} \Gamma^{-1}\right)=(\log \operatorname{det} \Gamma)^{\prime} \text { a.e. on }[0, \omega) \text {. }
$$

Proof. Observe that $\Gamma$ is a fundamental matrix for the differential equation $x^{\prime}=\Gamma^{\prime} \Gamma^{-1} x$; the result then follows immediately from the Liouville-Jacobi formula.

Throughout the following, the notation $H>0$, $\geqq 0$ etc. will mean that the matrix $H$ is positive definite, nonnegative definite, etc.

THEOREM 3. Let $H(t)$ be a nonsingular Hermitian matrix of absolutely continuous functions on $[0, \omega)$.

(a) If 


$$
H^{\prime}+A^{*} H+H A \leqq 0 \text { a.e. on }[0, \omega),
$$

then $x^{*} H x$ is nonincreasing, and $\tilde{x}^{*} H^{-1} \widetilde{x}$ is nondecreasing, whenever $x(t)$ and $\tilde{x}(t)$ are solutions of (1), and the adjoint of $(1)$, respectively.

(b) If (6) holds and $H>0$, then

$$
\lim _{t \rightarrow \omega}\left[\frac{1}{2} \log \operatorname{det} H(t)+\operatorname{Re} \int_{0}^{t} \operatorname{Tr} A\right]=-\infty
$$

is necessary and sufficient for the existence of a solution $x_{0}(t)$ such that $\lim _{t \rightarrow \omega} x_{0}^{*} H x_{0}(t)=0$. (7) is a sufficient condition for the existence of a solution $\widetilde{x}_{\infty}(t)$ of the adjoint of (1) such that

$$
\lim _{t \rightarrow \omega} \widetilde{x}_{\infty}^{*} H^{-1} \widetilde{x}_{\infty}(t)=+\infty \text {. }
$$

Proof of (a). (6) implies $\left(x^{*} H x\right)^{\prime} \leqq 0$ a.e. so $x^{*} H x$ is nonincreasing. Pre-multiplication of (6) by $-H^{-1}$ and post-multiplication by $H^{-1}$ shows $\left(H^{-1}\right)^{\prime}-A H^{-1}-H^{-1} A^{*} \geqq 0$ a.e., which implies $\left(\widetilde{x}^{*} H^{-1} \widetilde{x}\right)^{\prime} \geqq 0$ a.e.

Proof of (b). Let $\Gamma=H^{1 / 2}$, the unique positive definite square root of $H$. Then, $y(t)$ is a solution of (5) if and only if $y=\Gamma x$, where $x(t)$ is a solution of (1), and $\|y\|^{2}=x^{*} H x$. Therefore, by part (a), $0 \leqq \lim _{t \rightarrow \omega}\|y(t)\|<+\infty$ exists for each solution $y(t)$ of (5) and, by Corollary 1.2(a), $\Gamma \triangle A \in \Omega_{0}$ if and only if

$$
\lim _{t \rightarrow \omega} \operatorname{Re} \int_{0}^{t} \operatorname{Tr}(\Gamma \triangle A)=-\infty .
$$

But the lemma implies

$$
\operatorname{Tr}(\Gamma \triangle A)=(\log \operatorname{det} \Gamma)^{\prime}+\operatorname{Tr} A=\frac{1}{2}(\log \operatorname{det} H)^{\prime}+\operatorname{Tr} A,
$$

and hence (7) is necessary and sufficient for the existence of a solution $x_{0}(t)$ of (1) as described.

The assertion about the adjoint of (1) may be proved similarly, using Corollary 1.2(b). It also follows from the observation that there exists a solution $\widetilde{x}_{\infty}(t)$ of the adjoint of (1) such that

$$
1=\widetilde{x}_{\infty}^{*} x_{0}(t)=\widetilde{x}_{\infty}^{*} H^{-(1 / 2)} H^{1 / 2} x_{0}(t) \leqq\left[\widetilde{x}_{\infty}^{*} H^{-1} \widetilde{x}_{\infty}(t)\right]^{1 / 2}\left[x_{0}^{*} H x_{0}(t)\right]^{1 / 2}
$$

where $H^{-(1 / 2)}=\left(H^{1 / 2}\right)^{-1}=\left(H^{-1}\right)^{1 / 2}$.

Consider the scalar equation

$$
\left(p u^{\prime}\right)^{\prime}+q u=0,
$$

where $p$ and $q$ are real-valued measurable functions such that $1 / p$ and $q$ are locally integrable on $[0, \omega)$. 
COROLlaRY 3.1. (a) If $\alpha, \beta, \gamma$ are absolutely continuous realvalued functions on $[0, \omega)$ such that, for $t \in[0, \omega)$,

$$
\begin{gathered}
\alpha^{\prime}+\frac{2 \gamma}{p} \leqq 0, \quad \beta^{\prime}-2 \gamma q \leqq 0, \\
\left(\alpha^{\prime}+\frac{2 \gamma}{p}\right)\left(\beta^{\prime}-2 \gamma q\right)-\left(\gamma^{\prime}+\frac{\beta}{p}-\alpha q\right)^{2} \geqq 0,
\end{gathered}
$$

then, if $u$ is a solution of (8),

$$
E=\alpha\left(p u^{\prime}\right)^{2}+\beta u^{2}+2 \gamma u\left(p u^{\prime}\right)
$$

is nonincreasing while, if $\alpha \beta-\gamma^{2} \neq 0$ on $[0, \omega)$, then

$$
\widetilde{E}=\frac{1}{\alpha \beta-\gamma^{2}} E
$$

is nondecreasing.

(b) If (9) holds, and in addition

$$
\alpha>0, \alpha \beta-\gamma^{2}>0 \text { for } t \in[0, \omega),
$$

then

$$
\lim _{t \rightarrow \omega}\left(\alpha \beta-\gamma^{2}\right)(t)=0
$$

is necessary and sufficient for the existence of a solution, $u_{0}(t)$, of (8) such that $\lim _{t \rightarrow \omega} E(t)=0$; and is a sufficient condition for the existence of a solution of (8), $u_{\infty}(t)$, linearly independent of $u_{0}(t)$, such that $\lim _{t \rightarrow \omega} \widetilde{E}(t)=+\infty$.

Proof. Let $x_{1}=p u^{\prime}, x_{2}=u$, so that (8) is equivalent to the system

$$
x_{1}^{\prime}=-q x_{2}, x_{2}^{\prime}=\frac{1}{p} x_{1}
$$

which is of the form (1), with $\operatorname{Tr} A=0$. The adjoint of (11) is

$$
\widetilde{x}_{1}^{\prime}=-\frac{1}{p} \widetilde{x}_{2}, \widetilde{x}_{2}^{\prime}=q \widetilde{x}_{1}
$$

and the solutions of this equation are of the form $\widetilde{x}_{1}=u, \widetilde{x}_{2}=-p u^{\prime}$, where $u$ is any solution of (8). The corollary is an immediate consequence of Theorem 3 if we take

$$
H=\left[\begin{array}{ll}
\alpha & \gamma \\
\gamma & \beta
\end{array}\right] .
$$

(9) is equivalent to (6) and (10) is equivalent to (7) in this case. That 
$u_{0}$ and $u_{\infty}$ are linearly independent can be seen from the proof of Theorem 3, since

$$
1=\widetilde{x}_{\infty}^{*} x_{0}(t)=p\left(u_{\infty} u_{0}^{\prime}-u_{\infty}^{\prime} u_{0}\right)(t) .
$$

EXAmple 1. If $p q$ is absolutely continuous and positive then

$$
\alpha=\frac{1}{p q(0)} \exp \left(-\int_{0}^{t} \mu_{+}\right), \beta=\exp \left(-\int_{0}^{t} \mu_{-}\right) \text {and } \gamma=0
$$

satisfy (9), when $\mu=(\log p q)^{\prime}, \mu_{+}=\frac{1}{2}(|\mu|+\mu)$, and $\mu_{-}=\frac{1}{2}(|\mu|-\mu)$. Hence (8) has a solution $u_{0}(t)$, such that

$$
\lim _{t \rightarrow \omega}\left[\frac{\left(p u_{0}^{\prime}\right)^{2}}{p q(0)} \exp \left(-\int_{0}^{t} \mu_{+}\right)+u_{0}^{2} \exp \left(-\int_{0}^{t} \mu_{-}\right)\right]=0
$$

if and only if $\int_{0}^{\omega}|\mu|=+\infty$, and this is also a sufficient condition for the existence of a solution $u_{\infty}(t)$ such that

$$
\lim _{t \rightarrow \omega}\left[\left(p u_{\infty}^{\prime}\right)^{2} \exp \left(\int_{0}^{t} \mu_{-}\right)+u_{\infty}^{2} p q(0) \exp \left(\int_{0}^{t} \mu_{+}\right)\right]=+\infty .
$$

We can conclude, for example, that if

$$
\int_{0}^{\omega} \mu_{-}<+\infty \text { and } \int_{0}^{\omega} \mu_{+}=+\infty,
$$

then $\lim _{t \rightarrow \omega} u_{0}(t)=0$ for some solution of (8).

Special cases of Example (1) have been obtained by Milloux [7] and Hartman [4], under the assumption that $p q$ is positive and monotone and $\lim _{t \rightarrow \omega} p q=+\infty$. Here we have $p q$ positive but not necessarily monotone. In Example 2 we show that Corollary 3.1 may be applicable even when $p q$ is neither positive nor monotone, in fact we have $\lim \sup _{t \rightarrow \omega} p q=+\infty$ and $\lim \inf _{t \rightarrow \omega} p q=-\infty$.

ExAmPLe 2. Let $p(t)=2 e^{t}\left(1+e^{-t}\right), q(t)=\frac{1}{2} \operatorname{Sin} t, \omega=+\infty$,

$$
\alpha(t)=e^{-t}, \beta(t)=1+e^{-t} \text { and } \gamma(t)=0 .
$$

Then $\alpha^{\prime}(t)=-e^{-t}<0, \beta^{\prime}(t)=-e^{-t}<0$, and

$$
\left(\frac{\beta}{p}-\alpha q\right)^{2}(t)=\left(\frac{1}{2} e^{-t}-\frac{1}{2} e^{-t} \operatorname{Sin} t\right)^{2} \leqq e^{-2 t}=\alpha^{\prime} \beta^{\prime}(t) .
$$

Clearly (9) holds, and since $\lim _{t \rightarrow \infty} \alpha \beta(t)=0$ (i.e., (10) holds) and

$$
\beta(t) \geqq 1, \alpha p^{2}(t) \geqq 4 e^{t},
$$

it follows that there exists a solution $u_{0}(t)$ of 


$$
\left(e^{t}\left(1+e^{-t}\right) u^{\prime}\right)^{\prime}+\frac{1}{4}(\operatorname{Sin} t) u=0
$$

such that $\lim _{t \rightarrow \infty} u_{0}(t)=\lim _{t \rightarrow \infty} e^{t / 2} u_{0}^{\prime}(t)=0$.

In the preceding example the rapid smooth growth of the function $p$ helped to overcome the oscillatory behaviour of $q$. We now give an example to show that we can have $p(t)=1, \liminf _{t \rightarrow \omega} q(t)=$ $-\infty, \lim \sup _{t \rightarrow \omega} q(t)=+\infty$, and still be able to establish the existence of a zero-tending solution.

EXAmPle 3. Let $p=1, q=\left(1+\alpha+\alpha^{\prime}\right) / \alpha, \omega=+\infty$ in (8), where $\alpha^{\prime}(t)=0$ for $t \in(0,1)$,

$$
\begin{aligned}
& \alpha^{\prime}(t)=\left\{\begin{array}{c}
-n, t \in\left(n, n+\frac{1}{n^{3}}\right) \\
0, t \in\left(n+\frac{1}{n^{3}}, n+1\right)
\end{array} \quad n=1,2,3, \cdots,\right. \\
& \alpha(t)=\frac{\pi^{2}}{6}+\int_{0}^{t} \alpha^{\prime} .
\end{aligned}
$$

Note that $\lim _{t \rightarrow \infty} \alpha(t)=0, \liminf _{t \rightarrow \infty} q(t)=-\infty, \lim \sup _{t \rightarrow \infty} q(t)=+\infty$. Then we can choose $\gamma=0, \alpha$ as given, and $\beta=1+\alpha$ in Corollary 3.1 to conclude that there exists a solution, $u_{0}(t)$, of $u^{\prime \prime}+q u=0$ such that $\lim _{t \rightarrow \infty} u_{0}(t)=0$ and $\lim _{t \rightarrow \infty} \alpha(t)\left(u_{0}^{\prime}(t)\right)^{2}=0$.

Theorem 3 can also be applied to second order vector equations. Let $P$ and $Q$ be $n \times n$ matrices of complex-valued measurable functions on $[0, \omega)$ such that $P$ is nonsingular a.e., and $P^{-1}$ and $Q$ are locally integrable. Consider the system of differential equations

$$
\left(P x^{\prime}\right)^{\prime}+Q x=0,
$$

and its adjoint

$$
\left(P^{*} \widetilde{x}^{\prime}\right)^{\prime}+Q^{*} \widetilde{x}=0
$$

CoRollary 3.2. Let $P$ and $Q$ be as above.

(a) Suppose $S$ and $T$ are Hermitian matrices of absolutely continuous functions on $[0, \omega)$ such that

$$
\sigma_{M}^{1} \leqq 0, \tau_{M}^{1} \leqq 0, \sigma_{M}^{1} \tau_{M}^{1}-\left\|T P^{-1}-Q^{*} S\right\|^{2} \geqq 0 \text { a.e., }
$$

where $\sigma_{M}^{1}$ and $\tau_{M}^{1}$ are the largest eigenvalues of $S^{\prime}$ and $T^{\prime}$, respectively. Then

$$
E=x^{* \prime} P^{*} S P x^{\prime}+x^{*} T x
$$


is nonincreasing if $x(t)$ is a solution of (12). Furthermore, if $S$ and $T$ are nonsingular on $[0, \omega)$, then

$$
\breve{E}=\widetilde{x}^{*} S^{-1} \widetilde{x}+\widetilde{x}^{* \prime} P T^{-1} P^{*} \widetilde{x}^{\prime}
$$

is nondecreasing whenever $\widetilde{x}(t)$ is a solution of (13).

(b) If, in addition to the assumptions in part (a), we have $S>0$ and $T>0$, then

$$
\lim _{t \rightarrow \omega} \operatorname{det} S T(t)=0
$$

is a necessary and sufficient condition for (12) to possess a solution for which $\lim _{t \rightarrow \omega} E(t)=0$. In this case, (15) is also a sufficient condition for (13) to possess a solution for which $\lim _{t \rightarrow \omega} \widetilde{E}(t)=+\infty$.

Proof. We set

$$
z=\left[\begin{array}{c}
P x^{\prime} \\
x
\end{array}\right], A=\left[\begin{array}{lr}
0, & -Q \\
P^{-1}, & 0
\end{array}\right]
$$

and write (12) in the form of (1). The adjoint of $(1), \widetilde{z}^{\prime}=-A^{*}(t) \widetilde{z}$, will have solutions of the form

$$
\widetilde{z}=\left[\begin{array}{c}
\widetilde{x} \\
-P^{*} \widetilde{x}^{\prime}
\end{array}\right],
$$

where $\widetilde{x}$ is a solution of (13). We now apply Theorem 3, using

$$
H=\left[\begin{array}{ll}
S & 0 \\
0 & T
\end{array}\right] \text {. }
$$

The only nonroutine part remaining is to show that (14) implies $H^{\prime}+$ $A^{*} H+H A \leqq 0$ a.e. on $[0, \omega)$. Note first of all that $S^{\prime}$ and $T^{\prime}$ are Hermitian and nonpositive. It follows from a simple computation that

$$
H^{\prime}+A^{*} H+H A=\left[\begin{array}{cc}
S^{\prime} & F^{*} \\
F & T^{\prime}
\end{array}\right], F=T P^{-1}-Q^{*} S,
$$

and the associated (real-valued) quadratic form can be written

$$
x^{*} S^{\prime} x+y^{*} F x+x^{*} F^{*} y+y^{*} T^{\prime} y, x \text { and } y n \text {-vectors. }
$$

The values taken by this form are clearly bounded above by

$$
\sigma_{M}^{1}\|x\|^{2}+\tau_{M}^{1}\|y\|^{2}+2\|F\| \cdot\|x\| \cdot\|y\| \text {. }
$$

The remainder of the proof is now easily completed by applying Theorem 3. 
Corollary 3.2 is an improvement of results due to Hartman ([3], p. 502) and Coppel ([2], p. 61), one part of which can be stated as follows:

If, in (12), we have $P, Q$ commutative Hermitian continuously differentiable matrices, with $P Q>0$ and $(P Q)^{\prime} \geqq 0$, then

$$
R(t)=x^{*} x+x^{* \prime} P Q^{-1} x^{\prime}, x \text { a solution of }(12),
$$

is nonincreasing. Furthermore, (12) has a solution, $x_{0}(t)$, for which $\lim _{t \rightarrow \omega} R(t)=0$ if and only if $\lim _{t \rightarrow \omega} \operatorname{det} P Q=+\infty$.

This result follows immediately from Corollary 3.2 by choosing $T=I$ (the $n \times n$ identity matrix) and $S=P^{*-1} P Q^{-1} P^{-1}=(P Q)^{-1}$. The remainder of their results follow from the full statement of Corollary 3.2.

ExAMPLE 4. If there exists a matrix $\Phi$ such that $\Phi^{*} P^{-1}$ and $\Phi Q$ are absolutely continuous, Hermitian, and positive definite, with

$$
\left(\Phi^{*} P^{-1}\right)^{\prime} \leqq 0,(\Phi Q)^{\prime} \leqq 0 \text { a.e. on }[0, \omega),
$$

then the hypotheses of Corollary $3.2(a)$ are satisfied by

$$
S=\Phi^{*} P^{-1}, T=\Phi Q .
$$

This is easily verified by direct computation. For example, if either (i) $P^{*} Q$ or (ii) $P Q^{*}$ is absolutely continuous, Hermitian, and positive definite, then we may choose, respectively,

$$
S=I \exp \left(-\int_{0}^{t} \nu_{+}\right), T=P^{*} Q \exp \left(-\int_{0}^{t} \nu_{+}\right),
$$

or

$$
S=\left(P Q^{*}\right)^{-1} \exp \left(-\int_{0}^{t} \rho_{-}\right), T=I \exp \left(-\int_{0}^{t} \rho_{-}\right),
$$

where $\nu$ is the ratio of the largest eigenvalue of $\left(P^{*} Q\right)^{\prime}$ to the least eigenvalue of $P^{*} Q$, and $\rho$ is the ratio of the least eigenvalue of $\left(P Q^{*}\right)^{\prime}$ to the least eigenvalue of $P Q^{*}$. These cases correspond to choosing, respectively,

$$
\text { ( i ) } \Phi=P^{*} \exp \left(-\int_{0}^{t} \nu_{+}\right), \text {(ii) } \Phi=Q^{-1} \exp \left(-\int_{0}^{t} \rho_{-}\right) \text {. }
$$

That $\Phi$ satisfies the conditions outlined above can be verified by direct computation; for example, in case (i)

$$
T^{\prime}=(\Phi Q)^{\prime}=\left[\left(P^{*} Q\right)^{\prime}-v_{+} P^{*} Q\right] \exp \left(-\int_{0}^{t} \nu_{+}\right),
$$


and the choice of $\nu$ guarantees that $c^{*} T^{\prime} c \leqq 0$ for any complex $n$ vector $c$.

A somewhat sharper, but considerably less practical, result can be obtained in cases (i) and (ii) above by choosing $\nu$ as the largest eigenvalue of $N+N^{*}$, and $\rho$ as the smallest eigenvalue of $R+R^{*}$, where

$$
N=\left[\left(P^{*} Q\right)^{1 / 2}\right]^{\prime}\left(P^{*} Q\right)^{-(1 / 2)}, R=\left(P Q^{*}\right)^{-(1 / 2)}\left[\left(P Q^{*}\right)^{1 / 2}\right]^{\prime} .
$$

A differentiation of the quadratic forms, coupled with some simple manipulations, shows that $S^{\prime} \leqq 0, T^{\prime} \leqq 0$ in each case.

Remark (added in proof). Theorem 3 and its corollaries can be strengthened at the cost of making the hypotheses less concrete. The conditions (6), (9) and (14) are in each case specific sufficient conditions for property (2) to hold, in the sense that $\lim \inf _{t \rightarrow \omega} V(t)=0$ implies $\lim _{t \rightarrow \omega} V(t)=0$, where $V(t)$ is, respectively, $x * H x(t), E(t)$ as defined below (9), and $E(t)$ as defined below (14), in each case evaluated along solutions to the appropriate equation. We thank Professor H. Gollwitzer of Drexel University for his helpful comments on this and other matters.

\section{REFERENCES}

1. E. A. Coddington and N. Levinson, Theory of ordinary differential equations, McGraw-Hill, New York, 1955.

2. W. A. Coppel, Stability and asymptotic behavior of differential equations, D. C. Heath and Co., Boston, 1965.

3. P. Hartman, Ordinary differential equations, John Wiley and Sons, New York, 1964.

4. - The existence of large or small solutions of linear differential equations, Duke Math. J. 28 (1961), 421-429.

5. S. M. Lozinskii, Error estimates for the numerical integration of ordinary differential equations (Russian), Izv. Vyss. Ucebn. Zaved., Matematika (6) 5 (1958), 52-90.

6. L. Markus, Continuous matrices and the stability of differential systems, Math. Zeit. 62 (1955), 310-319.

7. H. Milloux, Sur l'equation differentielle $x^{\prime \prime}+A(t) x=0$, Prace Mat. Fiz. 41 (1934), 39-53.

8. G. Sansone and R. Conti, Nonlinear differential equations, Macmillan-Pergamon, New York, 1964.

Received June 2, 1969. This research was supported in part by the National Research Council of Canada, under grants NRC A-3053 and NRC A-7197.

University of Alberta 


\section{PACIFIC JOURNAL OF MATHEMATICS}

\section{EDITORS}

\author{
H. SAMELSON \\ Stanford University \\ Stanford, California 94305 \\ Richard Pierce \\ University of Washington \\ Seattle, Washington 98105
}

J. DUGUNDJI

Department of Mathematics

University of Southern California

Los Angeles, California 90007

RICHARD ARENS

University of California

Los Angeles, California 90024

\section{ASSOCIATE EDITORS}
E. F. BECKENBACH
B. H. NEUMaNN
F. WOLE
K. YosHIDA

\section{SUPPORTING INSTITUTIONS}

\author{
UNIVERSITY OF BRITISH COLUMBIA \\ CALIFORNIA INSTITUTE OF TECHNOLOGY \\ UNIVERSITY OF CALIFORNIA \\ MONTANA STATE UNIVERSITY \\ UNIVERSITY OF NEVADA \\ NEW MEXICO STATE UNIVERSITY \\ OREGON STATE UNIVERSITY \\ UNIVERSITY OF OREGON \\ OSAKA UNIVERSITY \\ UNIVERSITY OF SOUTHERN CALIFORNIA
}

\author{
STANFORD UNIVERSITY \\ UNIVERSITY OF TOKYO \\ UNIVERSITY OF UTAH \\ WASHINGTON STATE UNIVERSITY \\ UNIVERSITY OF WASHINGTON

$* * *{ }^{*} *{ }^{*}$
AMERICAN MATHEMATICAL SOCIETY
CHEVRON RESEARCH CORPORATION
TRW SYSTEMS \\ NAVAL WEAPONS CENTER
}

The Supporting Institutions listed above contribute to the cost of publication of this Journal. but they are not owners or publishers and have no responsibility for its content or policies.

Mathematical papers intended for publication in the Pacific Journal of Mathematics should be in typed form or offset-reproduced, (not dittoed), double spaced with large margins. Underline Greek letters in red, German in green, and script in blue. The first paragraph or two must be capable of being used separately as a synopsis of the entire paper. The editorial "we" must not be used in the synopsis, and items of the bibliography should not be cited there unless absolutely necessary, in which case they must be identified by author and Journal, rather than by item number. Manuscripts, in duplicate if possible, may be sent to any one of the four editors. Please classify according to the scheme of Math. Rev. 36, 1539-1546. All other communications to the editors should be addressed to the managing editor, Richard Arens, University of California, Los Angeles, California, 90024.

50 reprints are provided free for each article; additional copies may be obtained at cost in multiples of 50 .

The Pacific Journal of Mathematics is published monthly. Effective with Volume 16 the price per volume (3 numbers) is $\$ 8.00$; single issues, $\$ 3.00$. Special price for current issues to individual faculty members of supporting institutions and to individual members of the American Mathematical Society: $\$ 4.00$ per volume; single issues $\$ 1.50$. Back numbers are available.

Subscriptions, orders for back numbers, and changes of address should be sent to Pacific Journal of Mathematics, 103 Highland Boulevard, Berkeley, California, 94708.

PUBLISHED BY PACIFIC JOURNAL OF MATHEMATICS, A NON-PROFIT CORPORATION

Printed at Kokusai Bunken Insatsusha (Internatıonal Academic Printing Co., Ltd.), 7-17, Fujimi 2-chome, Chiyoda-ku, Tokyo, Japan. 


\section{Pacific Journal of Mathematics}

\section{Vol. 33, No. 3 \\ May, 1970}

Charles A. Akemann, Approximate units and maximal abelian

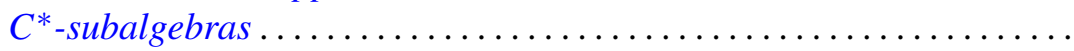

Gail Atneosen, Wild points of cellular arcs in 2-complexes in $E^{3}$ and cellular hulls

John Logan Bryant and De Witt Sumners, On embeddings of 1-dimensional

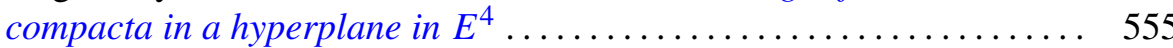

H. P. Dikshit, On a class of Nörlund means and Fourier series.......... 559

Nancy Dykes, Generalizations of realcompact spaces .............. 571

Hector O. Fattorini, Extension and behavior at infinity of solutions of certain linear operational differential equations .................. 583

Neal David Glassman, Cohomology of nonassociative algebras .......... 617

Neal Hart, Ulm's theorem for Abelian groups modulo bounded groups . . . . 635

Don Barker Hinton, Continuous spectra of second-order differential

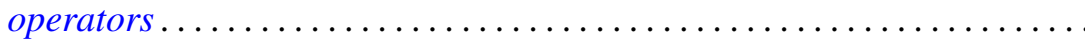

Donald Gordon James, On Witt's theorem for unimodular quadratic forms. II ............................................. 645

Melvin F. Janowitz, Principal multiplicative lattices................ 653

James Edgar Keesling, On the equivalence of normality and compactness in hyperspaces .................................... 657

Adalbert Kerber, Zu einer Arbeit von J. L. Berggren über ambivalente Gruppen

Keizō Kikuchi, Various $m$-representative domains in several complex variables

Jack W. Macki and James Stephen Muldowney, The asymptotic behaviour of solutions to linear systems of ordinary differential equations ....

Andy R. Magid, Locally Galois algebras . . . .

T. S. Ravisankar, On differentiably simple algebras......

Joseph Gail Stampfli, The norm of a derivation ..

Francis C.Y. Tang, On uniqueness of central decompositions of groups ...

749

Robert Charles Thompson, Some matrix factorization theorems. I .

763

Robert Charles Thompson, Some matrix factorization theorems. II . . 